\title{
PAPEL EDUCATIVO DO ENFERMEIRO E O LOCUS DE CONTROLE DA PESSOA DIABÉTICA
}

- Maria L. Zanetti - EERP - Dissertação de Mestrado - São Paulo, 1991.

A educação em saúde é a temática abordada, contexto do papel do enfermeiro enquanto educador, particularizando o paciente com diabetes mellitus cujos fatores pessoais e motivacionais interferem na aderência ao tratamento. $O$ trabalho teve como objetivo testar a fidedignidade do IMLCS (Instrumento de Medida de Locus de Controle à Saúde), confrontar a distribuição das respostas aos diferentes itens do IMLCS para duas populaçỏes distintas de pacientes diabéticos, assim como verificar a predominância do locus de controle à saúde nos sujeitos estudados. Para 0 alcance destes objetivos, foi aplicado um instrumento denominado: Instrumento de Medida de Locus de Controle à Saúde. Sua aplicação deu-se em duas etapas com populações distintas de diabéticos. Os dados obtidos de controle, permitiu-nos concluir que houve uma predominância dos sujeitos com o locus de controle extemo, que a distribuição das respostas aos diferentes itens nas duas etapas dos estudos foram diferentes e que a escala está validada para a população de pacientes diabéticos.

Escola de Enfermagem de Ribeirão Preto - Universidade de São Paulo

Av. Bandeirantes, n. 3900

CEP: 14.049 - Ribeirão Preto - SP - Fax: (016) 633-0567 